\title{
Letter
}

\section{An assessment of the RIFLE criteria for acute renal failure in critically ill HIV-infected patients}

\author{
José António Lopes ${ }^{1}$, Joana Fernandes ${ }^{2}$, Sofia Jorge ${ }^{1}$, José Neves ${ }^{2}$, Francisco Antunes ${ }^{2}$ \\ and Mateus Martins Prata ${ }^{1}$
}

\begin{abstract}
1Department of Nephrology and Renal Transplantation, Hospital de Santa Maria, Lisbon, Portugal
2Department of Infectious Diseases, Hospital de Santa Maria, Lisbon, Portugal
\end{abstract}

Corresponding author: José António Lopes, jalopes93@hotmail.com

Published: 9 January 2007

This article is online at http://ccforum.com/content/11/1/401

(c) 2007 BioMed Central Ltd
Critical Care 2007, 11:401 (doi:10.1186/cc5121)
Acute renal failure is common among hospitalized patients with HIV infection, particularly in the intensive care unit (ICU) setting, and increases mortality. Recently, the Acute Dialysis and Quality Initiative (ADQI) group [1] formulated a new classification for acute renal failure - the Risk, Injury, Failure, Loss, and End-stage kidney disease (RIFLE) classification that defines three grades of severity - class $R$ (risk), class $F$ (failure), and class I (injury) - and two outcome classes - loss and end-stage kidney disease. Some studies $[2,3]$ have applied the RIFLE criteria in hospitalized patients, particularly in ICU patients, but the clinical ability of these criteria to predict outcome of ICU HIV-infected patients has not yet been assessed. We sought to evaluate retrospectively the ability of the RIFLE criteria (Table 1) to predict outcome of the HIV-infected patients admitted to the Infectious Diseases ICU of our Hospital (Hospital de Santa Maria, Lisbon, Portugal) between January 2002 and June 2006. Chronic kidney disease patients receiving dialysis were excluded from the analysis. Mortality was assessed at day 60 [1]. We evaluated 97 HIV-infected patients (mean age $42.7 \pm 12.2$ years; 77 male, 69 Caucasian). According to RIFLE, 46 patients (47.4\%; mean age $43.2 \pm 11.08$ years, $P=$ not significant; 39 male, $P=$ not significant; 28 Caucasian, $P=$ not significant) had some degree of acute renal dysfunction. Of these, 12 patients (26\%) were class R, 9 patients (19.5\%) were class I, and 25 patients (54.3\%) were class F; these patients did not differ in terms of age, gender, race, type of HIV, stage of HIV infection, highly active antiretroviral therapy (HAART), comorbidity, and severity of illness. In all cases, maximum RIFLE occurred within the first week of hospitalization.

\section{Table 1}

\section{Risk, Injury, Failure, Loss, and End-stage kidney disease (RIFLE) classification}

\begin{tabular}{ll}
\hline Class & GFR criteria \\
\hline Risk & Serum creatinine $\times 1.5$ \\
Injury & Serum creatinine $\times 2$ \\
Failure & Serum creatinine $\times 3$ \\
& or serum creatinine $\geq 4 \mathrm{mg} / \mathrm{dl}$ with an acute rise $>0.5 \mathrm{mg} / \mathrm{dl} \quad<0.5 \mathrm{ml} / \mathrm{kg} / \mathrm{h} \times 6 \mathrm{~h} \mathrm{ml} / \mathrm{kg} / \mathrm{h} \times 12 \mathrm{~h} \quad<0.3 \mathrm{ml} / \mathrm{kg} / \mathrm{h} \times 24 \mathrm{~h}$ \\
Loss & Persistent acute renal failure $=$ complete loss of kidney function $>4$ weeks \\
End-stage kidney disease & End-stage kidney disease $>3$ months
\end{tabular}

For conversion of creatinine expressed in conventional units to ST units, multiply by 88.4. Patients are categorized on serum creatinine or urinary output (UO), or both, and the criteria that led to the worst classification are used. Glomerular filtration rate (GFR) criteria are calculated as an increase of serum creatinine above the baseline serum creatinine level. When the baseline serum creatinine is unknown and there is no past history of chronic kidney disease, serum creatinine is calculated using the Modification of Diet in Renal Disease formula for assessment of kidney function, assuming a glomerular filtration rate of $75 \mathrm{ml} /$ minute $/ 1.73 \mathrm{~m}^{2}$. Acute kidney injury should be considered when kidney dysfunction is abrupt (within 1 to 7 days) and sustained (more than 24 hours).

HAART = highly active antiretroviral therapy; ICU = intensive care unit; RIFLE = Risk, Injury, Failure, Loss, and End-stage kidney disease; SAPS = simplified acute physiology score. 
Overall mortality was $43.3 \%$ and increased significantly from normal to class $\mathrm{F}$ (normal, 23.5\%; class R, 50\%; class I, $66.6 \%$; and class F, 72\%; $P<0.0001)$. The majority of patients $(95 \%)$ died in the ICU within the first month of hospitalization. Multivariate regression analysis, including age, gender, comorbidity, RIFLE class and simplified acute physiology score (SAPS) II showed that only class I (odds ratio $5.12,95 \%$ confidence interval 1.07 to $24.28, P=0.04$ ) and class $F$ (odds ratio 4.6, 95\% confidence interval 1.57 to $13.5, P=0.005$ ), as well as SAPS II (odds ratio $1.04,95 \%$ confidence interval 1.01 to $1.07, P=0.005$ ) emerged as independent predictors of mortality. As SAPS II (area under receiver operating characteristic $0.699 \pm 0.055 ; P=0.001$ ), the RIFLE classification had good discriminative power (area under receiver operating characteristic $0.732 \pm 0.053$; $P<0.0001)$. In sum, acute kidney injury, defined by means of the RIFLE criteria, is common among critically ill HIV-infected patients, and RIFLE seems a helpful tool in the prognostic stratification of ICU HIV-infected patients.

\section{Authors' contributions}

JAL, JF, SJ made substantial contributions to conception and design, acquisition of data, and analysis and interpretation of data. JAL, JN, FA, and MMP were involved in drafting the manuscript and revising it critically for important intellectual content. All authors have given final approval of the version to be published.

\section{Competing interests}

The authors declare that they have no competing interests.

\section{References}

1. Bellomo R, Ronco C, Kellum JA, Mehta, RL, Palevsky P and the ADQI workgroup: Acute renal failure - definition, outcome measures, animal models, fluid therapy and information technology needs: the Second International Consensus Conference of the Acute Dialysis Quality Initiative (ADOI) Group. Crit Care 2004, 8:R204-R212.

2. Hoste EA, Clermont G, Kersten A, Venkataraman R, Angus DC, De Bacquer D, Kellum JA: RIFLE criteria for acute kidney injury are associated with hospital mortality in critically ill patients: a cohort analysis. Crit Care 2006; 10:R73.

3. Uchino S, Bellomo R, Goldsmith D, Bates S, Ronco C: An assessment of the RIFLE criteria for acute renal failure in hospitalized patients. Crit Care Med 2006, 34:1913-1917. 